\title{
TEKNOLOGI KOMUNIKASI PEMANDUAN WISATA: PROSPEK DAN TANTANGAN PEMANFAATAN APLIKASI JAWARA
}

\section{COMMUNICATION TECHNOLOGY OF TOURISM GUIDING: PROSPECTS AND CHALLENGES FOR UTILIZING JAWARA APPLICATION}

\author{
Purwadi $^{1}$ dan Irwansyah ${ }^{2}$ \\ ${ }^{1}$ Sekretariat Utama, Lembaga Ilmu Pengetahuan Indonesia \\ Jl. Gatot Subroto Kav. 10, Jakarta Selatan, DKI Jakarta, Indonesia \\ 1,2 Departemen Ilmu Komunikasi, Fakultas Ilmu Sosial dan Ilmu Politik, Universitas Indonesia \\ Gedung IASTH Lantai 6, Jl. Salemba Raya No. 4, Jakarta Pusat, DKI Jakarta, Indonesia \\ 1purwadi@lipi.go.id, 2dr.irwansyah.ma@gmail.com
}

Diterima: 24 Januari 2020

Direvisi: 07 Mei 2020

Disetujui: 08 Desember 2020

\begin{abstract}
This study analyzed the changes caused by the presence of a tourist guide application in Bogor botanical garden, namely Jelajah, Belajar dan Wisata di Kebun Raya (JAWARA), in several ways. First, it examined the development of the botanical garden tourism guiding method from conventional or human-based guidance to application-based guidance. Second, it investigated the prospects and challenges of using the JAWARA application as a tourist guide app. This study applied qualitative approach using literature review and interview techniques. The results of this study indicated that the botanical garden tourist guiding technique has changed significantly since the launch of the JAWARA application in 2018. Tour guiding, which was originally carried out conventionally, has gradually changed to application-based although at present it is still mixed with conventional method. It is not impossible in the future that application-based guidance would disrupt the conventional one if artificial intelligence replaced the role of conventional guidance. It is predicted that JAWARA application will develop massively along with the rapid use of digital communication technology, which increases the number of downloaders and users of this application. The challenge of using the JAWARA application is that this application must be kept up to date with the latest developments so that it can continue to be used optimally.
\end{abstract}

Keywords: Communication Technology, JAWARA Application, Guide, Tourism, Digital

\begin{abstract}
ABSTRAK
Penelitian ini berupaya menganalisis perubahan yang disebabkan oleh kehadiran aplikasi teknologi komunikasi pemanduan wisata kebun raya, yang bernama Jelajah, Belajar dan Wisata di Kebun Raya (JAWARA) dalam beberapa hal. Pertama, studi ini mengkaji perkembangan teknologi komunikasi pemanduan wisata kebun raya dari pemanduan konvensional ke pemanduan berbasis aplikasi. Kedua, tulisan ini membahas prospek dan tantangan pemanfaatan aplikasi JAWARA untuk pemanduan kebun raya. Penelitian ini menggunakan pendekatan kualitatif dengan metode studi literatur yang dikombinasikan dengan data hasil wawancara. Hasil penelitian ini menunjukkan bahwa terjadi perkembangan yang signifikan dalam pemanduan wisata kebun raya sejak diluncurkannya aplikasi JAWARA pada 2018. Pemanduan yang semula berbasis konvensional berubah secara perlahan menjadi berbasis aplikasi, meskipun saat ini masih bercampur dengan konvensional. Bukan tidak mungkin jika di masa depan pemanduan berbasis aplikasi akan menggantikan pemanduan konvensional manakala kecerdasan buatan mampu menggantikan peran dari pemanduan konvensional. Penggunaan aplikasi JAWARA memiliki prospek untuk berkembang secara masif seiring pesatnya penggunaan teknologi komunikasi digital yang mendorong meningkatnya jumlah pengunduh dan pengguna aplikasi ini. Adapun tantangan penggunaan aplikasi JAWARA adalah aplikasi ini harus terus terbarukan dengan perkembangan terkini agar dapat digunakan secara maksimal.
\end{abstract}

Kata Kunci: Teknologi Komunikasi, Aplikasi JAWARA, Pemandu, Wisata, Digital 


\section{PENDAHULUAN}

Kemunculan internet pada era 1990-an menandai kehadiran Revolusi Industri 3.0. Sejak saat itu, perkembangan internet menjadi begitu masif dan cepat. Imbas perkembangan internet yang paling kentara adalah pesatnya perkembangan teknologi informasi dan komunikasi (TIK). Perkembangan TIK semakin signifikan manakala memasuki Revolusi Industri 4.0 yang dimulai pada pergantian abad 21. Revolusi industri ini ditandai dengan sistem cyber-physical. Selain itu, penanda lainnya adalah kehadiran mobile internet yang lebih banyak dan tersebar di mana-mana, sensor yang berukuran lebih kecil, kuat, murah, serta adanya kecerdasan buatan dan mesin pembelajar. Revolusi Industri 4.0 menciptakan dunia yang memungkinkan sistem manufaktur virtual dan fisik secara global saling bekerja sama dengan cara yang fleksibel. Hal ini memungkinkan kustomisasi mutlak produk dan penciptaan model operasi baru. Pada dasarnya, Revolusi Industri 4.0 mempunyai skala yang lebih luas dengan ruang lingkup dan kompleksitas yang tinggi. Dampaknya telah membuat kemajuan teknologi baru, terutama teknologi digital, mengubah segala sendi kehidupan, mulai dari teknologi komunikasi, ekonomi, industri, pemerintahan, politik, dan lainnya (Schwab, 2016).

Terjadinya revolusi industri tersebut ternyata secara beriringan berdampak pada revolusi komunikasi. Behringer (2006) melihat bahwa revolusi komunikasi dapat dijelaskan sebagai proses historis makro, sebanding dengan revolusi ilmiah dan revolusi industri. Salah satu penanda revolusi komunikasi adalah kemunculan teknologi mobile. Teknologi ini membawa perubahan besar pada pengiriman informasi yang tidak lagi terbatas ruang dan waktu (Bolat, 2014). Teknologi mobile sendiri ada dan mulai berkembang pesat sejak kehadiran iPhone pada awal 2007. Sejak saat itu, orang dapat merasakan fungsionalitas komputer pribadi pada perangkat berukuran saku. Orang kemudian menyebutnya sebagai ponsel pintar atau smartphone, yang di dalamnya terdapat beragam aplikasi mobile. Dari situlah teknologi aplikasi bermunculan hingga sekarang (Rakestraw et al., 2013).

Kehadiran teknologi aplikasi mobile memang telah membawa dampak besar dalam berbagai lini kehidupan, salah satunya adalah pemanduan wisata, khususnya di kebun raya. Pemanduan wisata yang sebelumnya hanya mengandalkan pemanduan konvensional oleh manusia, perlahan telah berubah dan memunculkan sistem dan teknologi pemanduan baru yang berbasis aplikasi (digital). Kemunculan pemanduan berbasis aplikasi tersebut dilatarbelakangi oleh tuntutan zaman yang telah bergeser ke era digital. Era ini membuat Lembaga Ilmu Pengetahuan Indonesia (LIPI), melalui Pusat Konservasi Tumbuhan (PKT) Kebun Raya selaku pengelola kebun raya di Indonesia, mengembangkan aplikasi pemanduan wisata bernama Jelajah, Belajar dan Wisata di Kebun Raya (JAWARA) (Khusni. 2018.; Purwadi dan Irwansyah, 2019).

Keberadaan aplikasi JAWARA merupakan respons terhadap keterbatasan tenaga pemandu dan luasnya area kebun raya (Rahmawaty, 2017). Padahal, jumlah pengunjung empat kebun raya yang dikelola LIPI, yaitu Kebun Raya Bogor, Kebun Raya Cibodas, Kebun Raya Bali, dan Kebun Raya Purwodadi, meningkat dari waktu ke waktu. Sebagai contoh, Kebun Raya Bogor dikunjungi rata-rata 1.000 hingga 2.500 orang 
setiap hari di hari-hari biasa. Jumlah itu akan meningkat tatkala memasuki akhir pekan dan liburan. Jumlah pengunjung pada akhir pekan rata-rata sekitar 4.000 orang per harinya. Pada saat liburan, jumlah tersebut bisa melonjak menjadi 6.000 hingga 10.000 orang per hari (Suprapto, 2017).

Munculnya aplikasi JAWARA diprediksi akan melahirkan inovasi disruptif bagi sistem komunikasi pemanduan. Muncul kekhawatiran mengenai apakah pemandu berbasis aplikasi ini akan mengancam keberadaan pemandu konvensional dan membawa implikasi-implikasi lainnya? Berangkat dari hal tersebut, penelitian ini merumuskan dua masalah. Yang pertama, bagaimanakah perkembangan teknologi komunikasi pemanduan wisata kebun raya dari pemandu konvensional ke pemandu berbasis aplikasi? Aspek kedua adalah bagaimana prospek dan tantangan pemanfaatan aplikasi JAWARA untuk pemanduan kebun raya? Adapun tujuan penelitian ini adalah mencermati dan menganalisis perkembangan teknologi komunikasi pemanduan wisata kebun raya dari era pemandu konvensional ke pemandu berbasis aplikasi. Selain itu, penelitian ini juga mencermati prospek dan tantangan pemanfaatan aplikasi JAWARA untuk pemanduan kebun raya di masa depan. Dilihat dari segi manfaat, penelitian ini memberikan pengayaan pengetahuan tentang teknologi komunikasi pemanduan wisata kebun raya serta gambaran prospek dan tantangan pemanfaatan aplikasi pemanduan, khususnya aplikasi JAWARA, di masa kini dan mendatang. Dari sini, pemerintah dan pihak terkait dapat mengidentifikasi dan mempersiapkan kebijakan pemanduan wisata di masa depan. Dari sisi teknologi komunikasi, penelitian mengenai aplikasi JAWARA tidak jauh berbeda dengan studi tentang kemunculan beragam aplikasi di masa depan.

Selanjutnya, penelitian ini mempunyai dua konsep penting yang perlu dipaparkan. Yang pertama terkait dengan konsep teknologi komunikasi dalam konteks aplikasi mobile. Yang kedua terkait dengan aplikasi JAWARA sebagai aplikasi pemanduan wisata berbasis digital. Paparan pertama melihat bahwa teknologi komunikasi mobile merupakan teknologi yang membawa perubahan besar pada pengiriman informasi yang terbebas dari batasan ruang dan waktu. Teknologi ini juga menembus semua aspek sosial dan bisnis (Bolat, 2014). Jenis teknologi mobile ini beragam, mulai dari mobile phone (termasuk ponsel pintar), media mobile, hingga aplikasi mobile. Kemunculan teknologi mobile saling terkait dan diawali sejak tahun 2000 (Islam et al., 2010). Teknologi mobile sendiri berkembang pesat sejak keberadaan iPhone pada awal 2007. Telepon besutan Apple ini membuat pengguna dapat merasakan fungsionalitas komputer pribadi pada perangkat berukuran saku. Orang kemudian menyebutnya sebagai ponsel pintar dan di dalamnya terdapat beragam aplikasi dan media mobile. Teknologi mobile telah menjadi bagian penting kehidupan sehari-hari hingga kini (Rakestraw et al., 2013; Scolari et al., 2012).

Teknologi komunikasi mobile berkaitan erat dengan teknologi aplikasi. Aplikasi merupakan jenis perangkat lunak yang memungkinkan pengguna melaksanakan aktivitas-aktivitas tertentu dengan menginstal serta menjalankan berbagai perangkat digital dalam komputer atau perangkat digital portabel seperti ponsel pintar dan tablet (Islam et al., 2010; Liu et al., 2014). Aplikasi yang telah bertansformasi dalam teknologi mobile kerap disebut sebagai aplikasi mobile. Aplikasi 
mobile adalah aplikasi yang terdiri dari seperangkat program yang beroperasi di dalam perangkat seluler serta melaksanakan aktivitasaktivitas tertentu untuk pengguna. Aplikasi mobile merupakan segmen baru yang berkembang pesat secara global. Aplikasi mobile memiliki ciri-ciri mudah digunakan, ramah pengguna, murah, dapat diunduh dan dijalankan di sebagian besar telepon seluler, baik telepon kelas bawah maupun kelas atas. Aplikasi berbasis mobile mempunyai kegunaan yang beragam, antara lain panggilan, olah pesan, menjelajah dunia maya, mengobrol, komunikasi social network, audio, video, permainan, dan lainnya (Islam et al., 2010; Schmitz et al., 2016).

Aplikasi mobile memiliki beberapa karakteristik yang membedakannya dengan perangkat lunak pada umumnya. Perbedaan itu meliputi optimalisasi aplikasi mobile untuk perangkat seluler berbasis layar sentuh, desain sebagian besar aplikasi untuk penggunaan pribadi, dan ketentuan tidak berbayar (kecuali untuk biaya penggunaan data seluler) atau berbayar. Yang paling penting, aplikasi mobile bisa diunduh ke perangkat seluler secara langsung melalui pasar/toko online terpusat yang memungkinkan pengguna dapat memberi peringkat dan meninjau aplikasi serta mengakses berbagai daftar peringkat aplikasi (Liu et al., 2014).

Pada bagian selanjutnya akan dibahas tentang JAWARA sebagai aplikasi pemanduan pariwisata berbasis digital. JAWARA singkatan dari Jelajah, Belajar dan Wisata di Kebun Raya. Pembuatan dan pengembangan aplikasi ini bertujuan agar pengunjung kebun raya memiliki aplikasi pemandu digital yang membantu menjelajahi kebun raya dengan pemanduan mandiri, mudah, murah, aman, dan memiliki informasi yang disertai navigasi. Segala informasi mulai dari peta lokasi hingga hal-hal lain yang ada di kebun raya seperti bangunan cagar budaya, tanaman unik/langka, taman tematik, sarana publik, navigasi arah, dan lainnya, tersedia dalam aplikasi ini dengan akses yang mudah. Aplikasi ini dibuat oleh Tim Teknologi Informasi (TI) PKT Kebun Raya LIPI dengan konsep self-guided tour berbasis Android, free access, dan replicable. Manfaat aplikasi ini adalah memberikan kemudahan informasi mengenai objek/destinasi menarik, kejelasan informasi arah, kemudahan akses informasi dari ponsel, serta kemampuannya meningkatkan kunjungan ke kebun raya sehingga meningkatkan pendapatan kebun raya (Khusni. 2018.; Purwadi dan Irwansyah, 2019).

Untuk menggunakan aplikasi JAWARA, pengguna cukup mengunduhnya dari Google Play Store. Selanjutnya, pengguna dapat memasang aplikasi ini ke dalam ponsel pintar yang dimiliki. Setelah sukses melakukan pemasangan aplikasi pada ponsel, maka pengguna dapat mengakses aplikasi menggunakan internet protocol tanpa melalui proses login. Tangkapan layar aplikasi JAWARA dapat dilihat pada Gambar 1. 


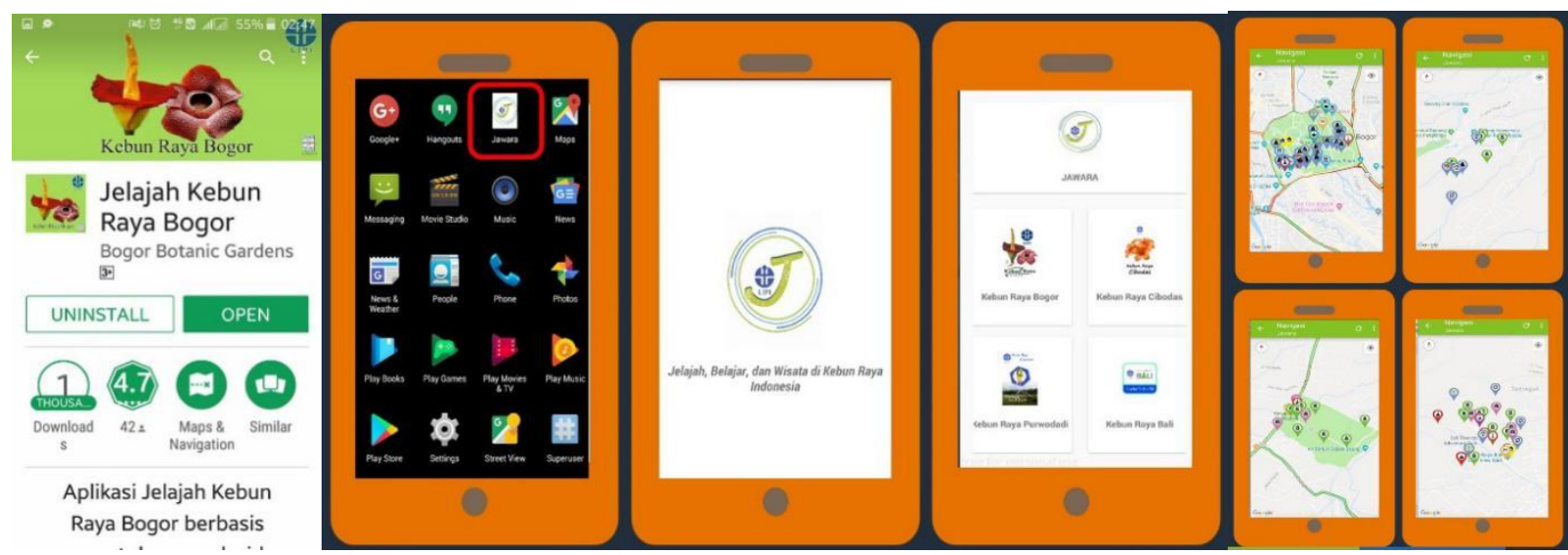

Gambar 1. Tangkapan Layar Aplikasi JAWARA Sumber: Khusni. 2018.

Sebelum kemunculan aplikasi JAWARA, telah ada beberapa penelitian sejenis yang dipublikasikan mengenai pemanfaatan aplikasi pemandu wisata. Penelitian pertama adalah yang dilakukan oleh Soedarsono dan Wiyancoko (2015) dan mengambil objek aplikasi Liku Bandung. Aplikasi ini didesain sebagai pusat informasi wisata, yang merupakan hasil pengembangan sistem dan sarana pemandu wisata bagi Kota Bandung. Aplikasi ini bertujuan untuk membantu wisatawan merencanakan dan menentukan perjalanan wisatanya di Ibukota Provinsi Jawa Barat tersebut. Aplikasi itu memungkinkan warga Kota Bandung memberikan input informasi langsung ke dalam aplikasi agar informasinya selalu update.

Penelitian lainnya adalah pengembangan aplikasi sistem pemandu wisata di Kota Cirebon, Jawa Barat. Aplikasi berbasis Android ini berfungsi sebagai penunjuk arah lokasi wisata di Kota Cirebon. Aplikasi tersebut memberi petunjuk kepada pengunjung atau wisatawan yang berkunjung ke Kota Cirebon layaknya pemandu wisata. Berbagai informasi yang tersedia dalam aplikasi itu antara lain adalah tempat wisata, hotel atau penginapan, restoran, tempat ibadah, transportasi umum, dan informasi publik lainnya (Nugroho et al., 2014).

Apabila dibandingkan dengan beberapa penelitian sebelumnya, penelitian ini lebih banyak mengarah ke ranah ilmu komunikasi ketimbang penelitian sebelumnya yang lebih banyak membahas ranah ilmu lain. Penelitian sebelumnya lebih banyak menelaah tentang teknis aplikasi seperti desain, pembuatan aplikasi, serta segi teknis lainnya dari aplikasi itu sendiri. Penelitian ini lebih menggali ilmu komunikasi dari aspek teknologi komunikasi pemanduan wisata, baik lewat pemanduan konvensional maupun pemanduan berbasiskan aplikasi. Selain itu, penelitian ini mencermati pula gambaran prospek dan tantangan pemanfaatan aplikasi pemanduan, seperti aplikasi JAWARA, di masa kini dan mendatang.

\section{METODOLOGI PENELITIAN}

Pendekatan dalam penelitian ini adalah kualitatif dengan metode deskriptif kualitatif. 
Metode deskriptif kualitatif adalah usaha pencarian fakta melalui interpretasi yang tepat dengan tujuan menggambarkan secara terperinci dan akurat (Neuman, 2014; Purwadi dan Irwansyah, 2019). Sumber data utama penelitian ini ialah wawancara dengan pengembang aplikasi JAWARA Kebun Raya Bogor LIPI dan data hasil studi literatur. Khusus untuk wawancara, wawancara dilakukan dengan informan utama, Uus Khusni, yang merupakan pengembang aplikasi JAWARA Kebun Raya Bogor LIPI. Dipilihnya informan ini didasari fakta bahwa beliau merupakan tokoh utama dalam pengembangan aplikasi JAWARA dan merupakan informan yang mengetahui seluk beluk aplikasi tersebut.

Adapun tahapan penelitian ini yang disarikan dari beberapa sumber (Bryman, 2012; Creswell, 2014) terdiri dari beberapa tahap, antara lain: (1) identifikasi masalah; (2) melakukan studi literatur; (3) menetapkan rumusan masalah atau pertanyaan penelitian; (4) menetapkan metode pengumpulan data; (5) mengelompokkan data penelitian sesuai dengan topik yang dikaji, yaitu teknologi komunikasi aplikasi mobile serta prospek dan tantangan pemanfaatan aplikasi untuk pemanduan kebun raya; (6) melakukan transkrip data hasil wawancara; (7) mengolah data hasil wawancara sesuai pokok bahasan penelitian, (8) mengombinasikan dan menyarikan hasil pengelompokan data studi literatur dan data hasil wawancara untuk pembahasan penelitian. Hasil ini meliputi teknologi komunikasi pemanduan kebun raya dari metode pemanduan konvensional ke metode pemanduan berbasis aplikasi serta prospek dan tantangan pemanfaatan aplikasi JAWARA untuk pemanduan kebun raya; serta (9) menuangkan hasil pembahasan ke dalam kesimpulan dan saran setelah pembahasan selesai.

\section{HASIL DAN PEMBAHASAN}

Dalam bagian ini akan diulas dua pokok bahasan. Pertama adalah pergeseran teknologi komunikasi pemanduan wisata kebun raya dari pemanduan konvensional ke pemanduan berbasis aplikasi. Adapun yang kedua ialah prospek dan tantangan pemanfaatan aplikasi JAWARA untuk pemanduan kebun raya.

Pembahasan pertama mencermati teknologi komunikasi pemanduan wisata kebun raya yang mulai ada sejak maraknya kunjungan wisatawan yang membutuhkan pemanduan ke kebun raya. Teknologi komunikasi pemanduan ini terbagi menjadi dua hal, yakni pemanduan konvensional dan pemanduan berbasis aplikasi. Perbedaan kedua jenis pemanduan tersebut ditunjukkan pada Tabel 1. 
Tabel 1. Perbedaan Pemanduan Konvensional dan Pemanduan Berbasis Aplikasi

\begin{tabular}{|c|c|c|}
\hline No & Pemanduan Konvensional & Pemanduan Berbasis Aplikasi \\
\hline 1. & $\begin{array}{l}\text { Masih menggunakan teknologi analog } \\
\text { atau berbasis manusia }\end{array}$ & $\begin{array}{l}\text { Menggunakan teknologi digital atau berbasis } \\
\text { aplikasi }\end{array}$ \\
\hline 2. & $\begin{array}{l}\text { Seluruh aspeknya (industri, produksi, } \\
\text { distribusi, dan konsumsi) masih } \\
\text { melibatkan manusia di dalamnya. }\end{array}$ & $\begin{array}{l}\text { Produksi, distribusi, dan konsumsi dalam } \\
\text { pemanduan berbasis aplikasi melibatkan } \\
\text { manusia dan teknologi informasi. }\end{array}$ \\
\hline 3. & $\begin{array}{l}\text { Masih mengenakan tarif jasa } \\
\text { pemanduan wisata. }\end{array}$ & $\begin{array}{l}\text { Tarif pemanduan gratis, namun akses data } \\
\text { untuk menjalankan aplikasi berbayar. }\end{array}$ \\
\hline 4. & $\begin{array}{l}\text { Jumlah orang yang dipandu oleh } \\
\text { pemandu wisata terbatas. Satu orang } \\
\text { pemandu hanya bisa melayani } \\
\text { beberapa belas atau puluh orang. }\end{array}$ & $\begin{array}{l}\text { Pemandu berbasis aplikasi tidak membatasi } \\
\text { jumlah orang yang dipandu. Semua } \\
\text { pengunjung kebun raya yang memasang } \\
\text { aplikasi ini dapat menggunakan layanannya. }\end{array}$ \\
\hline & $\begin{array}{l}\text { Kaya informasi sesuai dengan } \\
\text { pengetahuan sang pemandu. }\end{array}$ & $\begin{array}{lll}\text { Informasi terbatas pada teknologi yang } \\
\text { disediakan pada aplikasi. }\end{array}$ \\
\hline 6. & $\begin{array}{l}\text { Bahasa yang digunakan dalam } \\
\text { pemanduan bisa beragam, mulai dari } \\
\text { Bahasa Indonesia, Bahasa Inggris, } \\
\text { Bahasa Belanda, Jepang, dan lainnya. } \\
\text { Bahasa pemanduan tergantung pada } \\
\text { kemampuan bahasa para pemandu. }\end{array}$ & $\begin{array}{l}\text { Bahasa yang digunakan masih terbatas, yakni } \\
\text { Bahasa Indonesia dan Bahasa Inggris. }\end{array}$ \\
\hline 7. & $\begin{array}{l}\text { Pemanduan konvensional telah } \\
\text { berlangsung sejak kebun raya ada dan } \\
\text { kebutuhan pemanduan ini telah ada } \\
\text { sejak lama hingga sebelum tahun } \\
2015 \text {. }\end{array}$ & $\begin{array}{l}\text { Pemanduan aplikasi mulai dirintis sejak tahun } \\
2015 \text {. }\end{array}$ \\
\hline
\end{tabular}

Sumber: Diolah dari Rakestraw et al. (2013), Islam et al. (2010), wawancara dengan Uus Khusni pada 26 April 2019 , serta sumber untuk pemanduan manusia dari PKT Kebun Raya (2019) 
Tabel 1 menunjukkan perbedaan signifikan antara pemanduan konvensional dengan pemanduan berbasis aplikasi. Perbedaan penting yang perlu digarisbawahi adalah pemanduan konvensional mengandalkan seutuhnya pada kemampuan yang dimiliki oleh pemandu (manusia). Kebutuhan pemanduan oleh pemandu konvensional lebih dominan kepada informasi yang mendalam (Wawancara dengan Uus Khusni, 26 April 2019). Sementara itu, pemanduan berbasis aplikasi mengandalkan pada kemampuan aplikasi. Pemanduan ini muncul ketika pengguna terbiasa menggunakan aplikasi mobile (seluler). Aplikasi mobile berjalan pada perangkat seluler yang ringkas dan dapat dibawa dengan mudah oleh penggunanya, mudah digunakan, dan dapat diakses dari mana saja dan kapan saja (Islam et al., 2010).

Pada tahun 2000, pengembang aplikasi mobile mengembangkan aplikasi mobile berbasis internet. Dengan aplikasi mobile ini, pengguna kemudian dapat menghubungkan aplikasi mobile ke internet untuk kepentingan sehari-hari (Bolat, 2014; Islam et al., 2010). Seiring dengan berjalannya waktu, perkembangan aplikasi mobile pun semakin berkembang pesat sejak iPhone muncul pada pertengahan 2007 (Goggin, 2009 dalam Goggin, 2012).

Telepon seluler kemudian memasang beberapa aplikasi mobile sebagai layanan standar (default) dengan tetap menyediakan pilihan bagi pengguna untuk mengunduh dan memasang aplikasi lainnya. Berbagai aplikasi mobile dapat dijalankan di berbagai platform yang dikelola seperti iOS, BlackBerry, Android, Symbian, Windows; juga beberapa mesin virtual seperti Java/J2ME, BREW, FlashLight, dan Silverlight. Lewat aplikasi berbasis mobile, setiap orang dapat menggunakan aplikasi tersebut untuk menghubungi teman, menjelajahi internet, mengelola konten file, membuat dan menangani dokumen, hiburan, dan lainnya (Islam et al., 2010).

Sementara itu, jika dibandingkan antara pemanduan konvensional dan pemanduan berbasis aplikasi, maka informasi mendalam pada pemanduan konvensional menjadi hal utama dan belum tergantikan oleh pemanduan berbasis aplikasi saat ini. Hal ini disebabkan pemanduan berbasis aplikasi masih terbatas pada informasi yang disediakan di dalam aplikasi tersebut dan terkadang masih belum mendalam. Contohnya adalah aplikasi JAWARA. Aplikasi ini memiliki fitur-fitur pemanduan yang masih terbatas. Fitur-fitur yang ada masih sebatas pada fitur mapping lokasi hingga konten informasi seperti bangunan heritage, tanaman unik/langka, taman tematik, sarana publik, dan navigasi arah. Adapun untuk informasi atau konten di luar fitur yang ada di dalam aplikasi memerlukan penjelasan lebih detail oleh pemandu konvensional (Khusni. 2018.; Purwadi dan Irwansyah, 2019). Namun demikian, tidak menutup kemungkinan jika pemanduan berbasis aplikasi telah dapat menyediakan informasi mendalam, maka bisa saja pemanduan aplikasi benar-benar menggantikan peran pemanduan manusia (Wawancara dengan Uus Khusni, 26 April 2019).

Dengan demikian, dapat dicermati bahwa perkembangan pemanduan wisata kebun raya mengalami pergeseran signifikan dalam beberapa waktu terakhir, terbukti dengan adanya tren pemanfaatan pemandu berbasis aplikasi yang mulai masif (Lihat Tabel 2). Adalah sebuah keniscayaan ketika 
teknologi kecerdasan buatan berkembang pesat di masa depan, pemanduan berbasis aplikasi akan menggantikan fungsi pemanduan konvensional. Ketika disrupsi terjadi, maka pemanduan konvensional sangat mungkin digantikan oleh pemanduan berbasis aplikasi. Terlebih apabila fungsi kecerdasan manusia dapat dipindahkan ke dalam aplikasi sehingga mampu memberikan informasi mendalam yang dibutuhkan oleh penggunanya. Jika ini terjadi, maka pemanduan berbasis aplikasi akan benar-benar menggantikan fungsi pemanduan konvensional.

Kendati demikian, proses disrupsi dari pemanduan konvensional ke pemanduan berbasis aplikasi belum tampak masif saat ini. Penelitian ini memperlihatkan bahwa kebutuhan pemanduan konvensional belum sepenuhnya dapat digantikan oleh pemanduan berbasis aplikasi. Kedua jenis pemanduan ini saling melengkapi (Wawancara dengan Uus Khusni, 26 April 2019). Praktik pemanduan yang dilakukan masih bercampur antara pelibatan manusia dan aplikasi dalam proses produksi, distribusi, dan konsumsi layanannya. Proses produksi mencakup konten/informasi dari pemanduan, distribusi merupakan proses penyampaian konten/informasi pemanduan kepada pengguna selaku konsumen. Adapun konsumsi ialah layanan konten/informasi yang diterima oleh pengguna pemanduan (Wawancara dengan Uus Khusni, 26 April 2019).

Beralih ke pembahasan kedua terkait prospek dan tantangan penggunaan aplikasi JAWARA, maka pembahasan dimulai dengan prospek penggunaan aplikasi tersebut. Sejak diluncurkan dengan nama baru JAWARA pada April 2018, aplikasi ini mengalami perkembangan cukup signifikan dalam penggunaan dan pengunduhan oleh para pengguna. Perkembangan itu ditunjukkan pada Tabel 2.

Tabel 2. Perbandingan Instal Aplikasi JAWARA dengan Pemanduan Konvensional Tahun 2018

\begin{tabular}{lcccccccccccc}
\hline & $(\mathbf{1})$ & $(\mathbf{2})$ & $\mathbf{( 3 )}$ & $\mathbf{( 4 )}$ & $\mathbf{( 5 )}$ & $\mathbf{( 6 )}$ & $\mathbf{( 7 )}$ & $\mathbf{( 8 )}$ & $\mathbf{( 9 )}$ & $\begin{array}{c}(\mathbf{1 0}) \\
\text { Okt }\end{array}$ & $\begin{array}{c}(\mathbf{1 1}) \\
\text { Nov }\end{array}$ & $\begin{array}{c}(\mathbf{1 2}) \\
\text { Des }\end{array}$ \\
\hline JAWARA & & & & 13 & 29 & 260 & 208 & 115 & 122 & 116 & 109 & 155 \\
\hline Konvensional & 1.363 & 1.388 & 2.668 & 1.827 & 1.920 & 251 & 1.371 & 1.111 & 1.176 & 3.816 & 2.669 & 1.670 \\
\hline
\end{tabular}

Sumber: Khusni. 2018.

Jika dibandingkan dengan pemanduan konvensional, terdapat gap yang cukup besar dalam hal pemanfaatannya. Hal ini dapat dipahami mengingat aplikasi JAWARA yang baru mulai beroperasi sejak bulan April dan diposisikan sebatas pelengkap dari pemanduan konvensional saat ini. Berdasarkan tren pada Tabel 2, pemanduan berbasis aplikasi JAWARA dan pemanduan konvensional samasama mengalami fluktuasi pada angka penggunaannya. Hal menarik terlihat pada rentang November hingga Desember, tren pemanduan konvensional cenderung mengalami penurunan sementara instalasi aplikasi pemanduan JAWARA cenderung naik.

Instalasi aplikasi JAWARA diprediksi akan terus naik walaupun tetap mengalami fluktuasi dalam proses kenaikannya. Prediksi ini merujuk pada karakteristik pengunduhan aplikasi berbasis Android dan aplikasi dari Google Play Store yang mengalami kenaikan dari waktu ke waktu (Burgers et al., 2016; Etro dan Caffarra, 2017). Hal ini memperlihatkan prospek yang baik dari pemanfaatan aplikasi 
JAWARA seiring dengan semakin banyaknya pengunduh dan pengguna aplikasi ini. Apalagi, aplikasi ini juga mendapatkan rating positif di toko aplikasi, seperti ditunjukkan pada Gambar 2 .

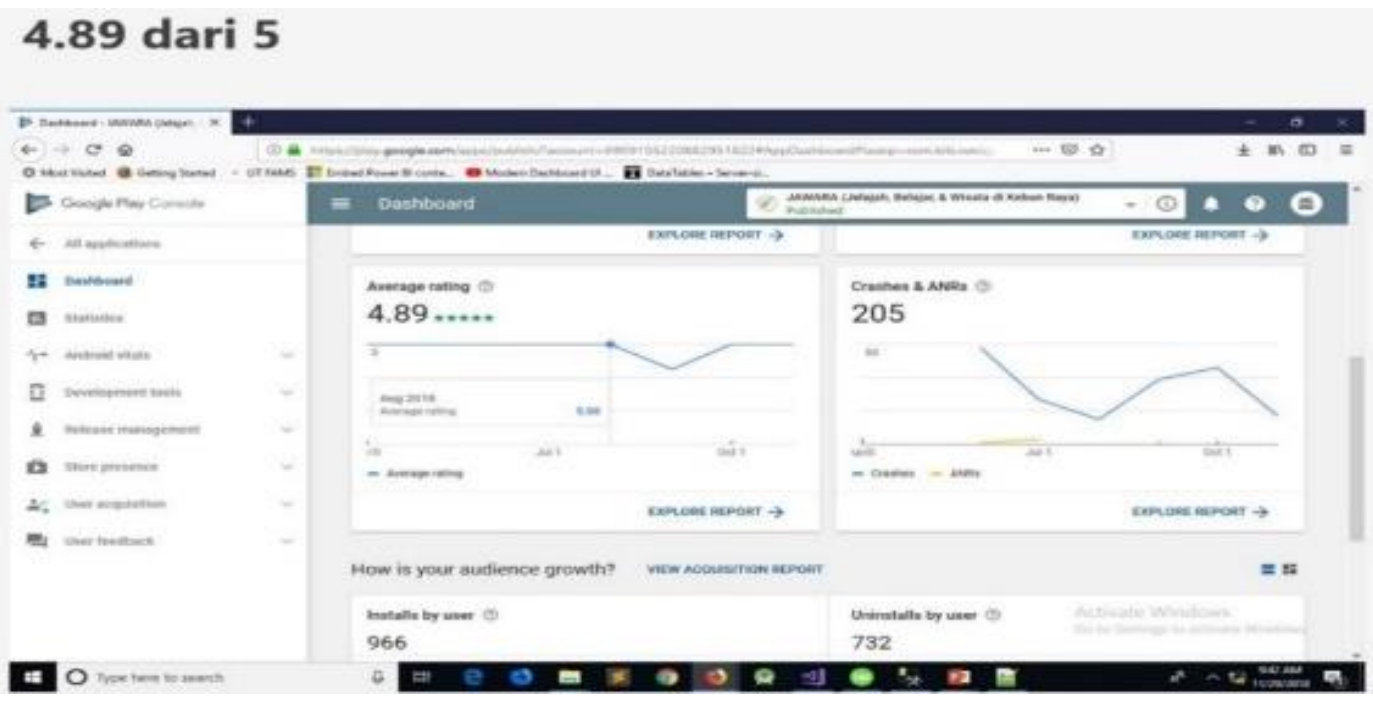

Gambar 2. Rating Aplikasi JAWARA di Google Play Store Sumber: Khusni. 2018.

Meskipun diprediksi memiliki prospek yang baik dari segi pengunduhan dan penggunaannya, namun aplikasi pemanduan JAWARA bukan tanpa kekurangan. Beberapa kekurangan dari aplikasi ini adalah masih terbatasnya fitur-fitur untuk pemanduan dan perlu ditambah lagi agar lebih lengkap. Kemudian, beberapa fitur terkadang mengalami error dan kurang akurat konten/informasinya. Hal ini tentu mengganggu dan perlu pembenahan yang cepat dan akurat. Tim TI dan manajemen kebun raya pun berupaya sebaik mungkin untuk memperbaiki kekurangan tersebut (Wawancara dengan Uus Khusni, 26 April 2019).

Selain memperbaiki kekurangan yang ada, penggunaan aplikasi JAWARA juga terus diupayakan. Beberapa upaya itu ialah perlunya dilakukan sosialisasi penggunaan aplikasi JAWARA secara terus-menerus untuk menjaga tersebut. Aspek sosialisasi ini penting guna menanamkan kesadaran kepada masyarakat untuk menggunakan aplikasi JAWARA. Uus Khusni menuturkan bahwa sosialisasi aplikasi JAWARA telah dilakukan dalam beberapa tahapan. Pertama, sosialisasi melalui petugas loket dan spanduk tentang aplikasi JAWARA di spot-spot masuk loket kebun raya. Kedua, sosialisasi melalui media massa tentang aplikasi JAWARA. Ketiga, sosialisasi aplikasi JAWARA lewat situs web kebun raya maupun LIPI. Keempat, sosialisasi aplikasi ini melalui pemandu (manusia) melalui gerakan mengajak pengunjung kebun raya untuk melakukan pemasangan aplikasi JAWARA. Kelima, sosialisasi lewat kerja sama dengan Google yang menyediakan Google Station Wifi secara gratis untuk pemasangan aplikasi JAWARA di telepon seluler. Keenam, menyiapkan aplikasi JAWARA agar dapat juga diunduh di toko 
aplikasi lainnya seperti Apple Store (Wawancara dengan Uus Khusni, 26 April 2019).

Ke depannya, aplikasi JAWARA akan dibuat versi iOS. Lalu, akan ada penambahan fitur di dalam aplikasi berupa koleksi khas kebun raya yang saat ini masih belum masuk ke dalam aplikasi. Dengan rencana pengembangan ini, aplikasi JAWARA diharapkan tidak sebatas aplikasi yang memandu pengunjung saja, namun juga ada unsur edukasi yang menonjol pada aplikasi itu (Wawancara dengan Uus Khusni, 26 April 2019).

Di sisi lain, pemanfaatan aplikasi JAWARA sendiri sejak kemunculannya hingga sekarang ini menghadapi beragam tantangan. Menurut Khusni (2019), tantangan yang dihadapi dalam pengembangan aplikasi ini ada dua, yaitu tantangan internal dalam pengelolaan dan pengembangan serta tantangan eksternal dari pengguna dan pembaruan aplikasi mengikuti perkembangan terkini. Tantangan internal dalam pengelolaan dan pengembangan mencakup: (1) pengelolaan aplikasi JAWARA yang belum terlembagakan dengan baik, karena status tim pengelola masih bersifat ad hoc; (2) karena pengelolaan yang belum terlembagakan, maka pengembangan aplikasi belum berjalan maksimal, terutama untuk penambahan fiturfitur baru; serta (3) respons terhadap keluhan pengguna yang kurang cepat karena kendala koordinasi teknis antarpengelola. Untuk menghadapi ketiga tantangan ini, maka perlu dibentuk tim yang kuat dan permanen dalam mengelola dan mengembangkan aplikasi JAWARA. Selain itu, koordinasi teknis antara pimpinan dan anggota pengelola perlu terus ditingkatkan agar segala keluhan dapat direspons dengan cepat.

Adapun tantangan eksternal dari pengguna sesuai hasil monitoring dan evaluasi yang dilakukan oleh pihak pengelola aplikasi Jawara pada tahun 2018 mencakup: (1) keluhan pengguna terhadap akurasi peta yang belum terlalu baik pada aplikasi JAWARA, (2) keluhan pengguna tentang borosnya konsumsi baterai ketika menggunakan aplikasi tersebut, (3) keluhan pengguna tentang borosnya konsumsi data internet pada aplikasi JAWARA, (4) adanya rencana komersialisasi fitur peta pada Google, serta (5) persaingan penggunaan aplikasi pemandu serupa (Wawancara dengan Uus Khusni, 26 April 2019).

Untuk menghadapi lima tantangan tersebut, hal yang perlu dilakukan oleh pengelola aplikasi adalah merespons sebaik mungkin saran dan kritik dari para pengguna. Tindak lanjut dari pengelola aplikasi meliputi: 1) perbaikan akurasi posisi peta di aplikasi; 2) perbaikan terhadap konsumsi daya baterai dan konsumsi data internet; 3) kerja sama dengan Google terkait komersialisasi peta pada Google; 4) terkait dengan persaingan dengan aplikasi pemandu serupa, pengelola terus melakukan update dengan perkembangan terkini (Wawancara dengan Uus Khusni, 26 April 2019). Prinsip pengembangan aplikasi JAWARA juga harus fleksibel. Artinya, sistem harus selalu memudahkan pengguna untuk mengaksesnya dari waktu ke waktu (Alshattnawi, 2013). Aspek lainnya, aplikasi JAWARA perlu menciptakan layanan bernilai tambah, sekaligus mengatasi keterbatasan perangkat seluler (Jinendra R. et al., 2012).

\section{KESIMPULAN DAN SARAN}

Berdasarkan hasil analisis terhadap temuan penelitian dapat disimpulkan bahwa perkembangan industri pemanduan wisata kebun raya mengalami perubahan signifikan dalam beberapa waktu belakangan ini. 
Perubahan tersebut dapat dilihat sejak kemunculan aplikasi JAWARA pada April 2018 hingga sekarang. Pemanduan yang semula hanya mengandalkan metode konvensional, berubah secara perlahan ke pemanduan berbasis aplikasi yang masih bercampur dengan konvensional saat ini. Bukan tidak mungkin bahwa di masa depan, pemanduan berbasis aplikasi berpotensi menggantikan pemanduan konvensional. Hal itu akan terjadi jika kecerdasan buatan mampu menggantikan peran dari pemanduan konvensional. Penggunaan aplikasi JAWARA berpotensi akan berkembang secara masif seiring pesatnya penggunaan teknologi komunikasi digital yang mendorong meningkatnya jumlah pengunduh dan pengguna aplikasi itu. Tantangan penggunaan aplikasi JAWARA terletak pada kemampuannya untuk terus menyesuaikan diri dengan perkembangan terkini agar terus dapat digunakan secara maksimal. Diharapkan agar pengelola aplikasi dapat mencarikan solusi terhadap segala kendala dalam pengembangan aplikasi ini agar tidak menghambat optimalisasi penggunaan aplikasi JAWARA bagi penggunanya.

Di masa mendatang, prospek penggunaan aplikasi JAWARA terbilang bagus. Kendati demikian, prospek yang cerah dari aplikasi JAWARA ini perlu diikuti sejumlah langkah, seperti: (1) aspek sosialisasi yang perlu terus digencarkan, (2) pengembangan aplikasi JAWARA tidak hanya dilakukan di Google Play Store saja, tetapi perlu pula di Apple Store, (3) tim pengelola aplikasi JAWARA perlu lebih memperkaya konten aplikasi, serta (4) tim pengelola aplikasi ini perlu menonjolkan fitur edukasi yang seimbang dengan fitur jelajah lapangan. Dengan penerapan langkah-langkah ini, diharapkan prospek aplikasi JAWARA ke depan semakin baik lagi.

\section{UCAPAN TERIMA KASIH}

Penelitian ini terlaksana dengan bantuan dan dukungan berbagai pihak. Penulis mengucapkan terima kasih kepada para pimpinan dan pengelola beasiswa Saintek Kementerian Riset dan Teknologi/Badan Riset dan Inovasi Nasional sebagai sponsor utama; serta para pimpinan dan pihak-pihak terkait lainya di LIPI dan Universitas Indonesia. Untuk penulisan artikel ini, Purwadi merupakan kontributor utama sedangkan Irwansyah merupakan pembimbing dan kontributor anggota.

\section{DAFTAR PUSTAKA}

Alshattnawi, S. (2013). Building Mobile Tourist Guide Applications using Different Development Mobile Platforms. International Journal of Advanced Science and Technology, 54(May), 13-22.

Behringer, W. (2006). Communications Revolutions: A Historiographical Concept. German History, 24(3), 333374.

https://doi.org/10.1191/0266355406gh37 8 oa

Bolat, E. (2014). Why to Use Mobile Technology? Academy of Marketing Conference, 1-7.

Bryman, A. (2012). Social Research Methods (4th Ed.). Oxford University Press.

Burgers, C., Eden, A., de Jong, R., \& Buningh, S. (2016). Rousing reviews and instigative images: The impact of online reviews and visual design characteristics on app downloads. Mobile Media and Communication, 4(3), 327-346. 
https://doi.org/10.1177/20501579166393 48

Creswell, J. W. (2014). Research Design: Qualitative, Quantitative, and Mixed Methods Approaches (4th Ed.). Sage Publications.

Etro, F., \& Caffarra, C. (2017). On the economics of the android case. European Competition Journal, 13(2-3), 282-313. https://doi.org/10.1080/17441056.2017.1 386957

Goggin, G. (2012). Google phone rising: The Android and the politics of open source. Continuum: Journal of Media \& Cultural Studies, 26(5), 741-752. https://doi.org/10.1080/10304312.2012.7 06462

Islam, R., Islam, R., \& Mazumder, T. (2010). Mobile Application and Its Global Impact. International Journal of Engineering \& Technology (IJEST), 10(06), 72-78. http://ijens.org/1075060909 IJET-IJENS.pdf

Jinendra R, D., Bhagyashri R, J., Pranav Y, G., Seema U, V., \& Parag N, A. (2012). Smart Travel Guide: Application for Android Mobile. 1st International Conference on Recent Trends in Engineering \& Technology, March, Page 115-121.

Khusni, U. (2018). Laporan Aplikasi JAWARA (Jelajah, Belajar dan Wisata di Kebun Raya) Tahun 2018.

Khusni, U. (2019). Wawancara Personal tentang Aplikasi JAWARA.

Liu, C. Z., Au, Y. A., \& Choi, H. S. (2014). Effects of Freemium Strategy in the Mobile App Market : An Empirical Study of Google Play. Journal of Management Information Systems, 31(3), 326-354. https://doi.org/10.1080/07421222.2014.9
95564

Neuman, W. L. (2014). Social Research Methods: Qualitative and Quantitative Approaches. In Pearson Education Limited (7th Ed.). Pearson Education Limited. https://doi.org/10.1234/12345678

Nugroho, T. B., Iqbal, M., \& Rohmah, Y. S. (2014). Aplikasi Sistem Pemandu Wisata Di Kota Cirebon Berbasis Android. JETT: Jurnal Elektro Dan Telekomunikasi Terapan UniversitasTelkom, 51-58.

PKT Kebun Raya. (2019). Pemanduan. PKT Kebun Raya. http://krbogor.lipi.go.id/id/Pemanduan

Purwadi, P., \& Irwansyah, I. (2019). Aplikasi JAWARA: Pemandu Digital Terasa seperti Pemandu Berbasis Komunikasi Analog? Jurnal Penelitian Komunikasi, 22(2), 123-138. https://doi.org/10.20422/jpk.v22i1.609

Rahmawaty, L. (2017). Kebun Raya Bogor miliki aplikasi jelajah. Antaranews.Com. https://www.antaranews.com/berita/6583 01/kebun-raya-bogor-miliki-aplikasijelajah

Rakestraw, T., Eunni, R., \& Kasuganti, R. (2013). The mobile apps industry: A case study. Journal of Business Cases and Applications, $\quad 9, \quad 26$. http://search.ebscohost.com/login.aspx?di rect $=$ true \& profile $=$ ehost $\&$ scope $=$ site $\&$ aut htype $=$ crawler $\&$ jrnl $=23277068 \& A N=904$ 40385\&h=7RQ+BpTgE1ySzhBy1cRxV B3wmKr1J7b/nWkcyS/9z2dd4kM9i4WT 5Et54ImCIAf2Kj3JLrgNoJ1W/Cea5UpF $\mathrm{Xw}==\& \mathrm{crl}=\mathrm{c}$

Schmitz, C., Bartsch, S., \& Meyer, A. (2016). Mobile App Usage and its Implications for Service Management - Empirical 
Findings from German Public Transport.

Procedia - Social and Behavioral

Sciences, 224(August 2015), 230-237. https://doi.org/10.1016/j.sbspro.2016.05. 492

Schwab, K. (2016). The Fourth Industrial Revolution. In World Economic Forum. World Economic Forum. www.weforum.org

Scolari, C. A., Aguado, J. M., \& Feijóo, C. (2012). Mobile Media: Towards a Definition and Taxonomy of Contents and Applications. International Journal of Interactive Mobile Technologies (IJIM), 6(2), 29-38. https://doi.org/10.3991/ijim.v6i2.1880

Soedarsono, I. B., \& Wiyancoko, D. (2015). Desain Sistem dan Sarana Pemandu Wisata untuk Kota Bandung. Jurnal Tingkat Sarjana Senirupa Dan Desain, 1(1), 1-7.

Suprapto. (2017). Aplikasi Jelajah Kebun Raya Bogor.

RRI. http://rri.co.id/yogyakarta/post/berita/446 822/warna_warni/aplikasi_jelajah_kebun _raya_bogor.html 